\title{
Assessing Factors Accelerating Gender Inequality in Tanzania Education System: Mien of Imperative Government Policy for Development
}

\author{
Bertha Wilfred Bisanda* \\ University of Science and Technology of China, Department of Public Affairs, \\ Anhui Hefei, 230026, Hefei, China \\ Prof Wan Ming \\ University of Science and Technology of China, Department of Public Affairs, \\ Anhui Hefei. 230026, Hefei, China.
}

\begin{abstract}
The gender inequality is a very concerning issue in our current society, culture, and communities affecting many developing nations. This goes against the first article of The Declaration of Human Rights; all human species have the liberty and equal rights in dignity to education. The aim of this research is born to examine and explore accelerators of gender inequality education of Tanzania and strategic government policy on higher education. The study uses inductive qualitative and from relevant documents collections using interviews through Likert scale questionnaires. The target populations of 350 from four selected universities of Tanzania, educationist, and community members. Demographically, represented male 303 is $86.6 \%$, and female served 47 of $13.7 \%$, using the SPSS v. 23 for the analysis. Findings reveal on gender inequality, effects on management strategies all correlated to women empowerment. However, government policy strategic was predictively significant to the entire study. The study found that responsibilities distributed on gender biases base on culture, poverty, ignorance, must to inept by strategic government policy in Tanzanian education.
\end{abstract}

Keywords: Acceleration, Gender Inequality, Education, Government Policy, Tanzania, Development.

DOI: 10.7176/PPAR/9-5-05

Publication date:May $31^{\text {st }} 2019$

\section{Introduction}

The gender inequality is a very concerning issue in our current society and affects many developing nations most especially Tanzanian case. This problem arises when a person receives unequal or disadvantageous treatment, under the same circumstances, based on gender. This goes against the first article of The Declaration of Human Rights, "All human species are born free and equal rights for dignity. They are embedded with logical consciousness to act towards one another in the unity of purpose. Education is a crucial principle for any lowincome economy in advancing the socio-cultural and economic development for better prospects. Gender to education is directly proportional to gender equity in the labor force, in the household and decision-making. Educating the female's lowers infant mother and baby mortality rates that goes to affect higher educational attainment and achievement for next generations and improve the economic conditions of nations (Target, 2015). On all these, education is still the realization point of focus, whereas the cardinal on female education a critical issue within the African sub-regions and in most developing parts of the world at large. Gender discrimination is a social phenomenon, preventing women participation in important discussions like; developments, cultural, economic, social, and political life of society. Discrimination and lack of societal understanding about women's issues such as violence against women make it difficult for them to become successful in the workplace (HRCPakistan, 2015). In many societies, women often neglected rather than encouraged to perform gender-related activities by parents and the community (Eagly \& Wood, 2012).

Nevertheless, equality in education among gender is critical that needs international discussions on policies framework for sustainable development for equity accentuation of development. The national focus of Tanzanian education policy should shift on encouraging similar distributions of education access, quality and ensuring fairness. The knowledge of women education generally viewed as a better economic decision for the developing world (RTI International, 2016).

In a broader report assessment of the Swedish Agency for Development of Evaluation (SADEV, 2011), education primarily chosen as a target to attain the third Millennium Development Goal (MDG3), which is to promote gender equality and women empowerment. The objective is, "the elimination of gender disparity in primary and secondary by 2005 and at all levels of education by 2015'. The rationale for gender equality perspective in education implies a rights perspective as well development perspective (Sumra, 2017). Education is a right but not a privilege for women's empowerment. Education is enabling venue for both sexes to participate in socio-economic and political life and a basic factor for the development of governance across 
societies (Benavot et al., 2016). The social, economic benefits of education known since time immemorial, also advantageous for the proper upbringing of societies education of girls and women phenomenal drawn upon passive of equal access (United Nations Educational Scientific and Cultural Organization, 2018). Gender equality needs intensification of avenues for the development focus on the various approach of access to and quality of education, both related to gender equality (Reid \& Shams, 2013). Education remains the most fundamental human right for all people and nations, so equality of gender in education is critical for all ages (Simwaka, Theobald, Amekudzi, \& Tolhurst, 2005). Basic sector of education; literacy skills, facilities for educations, therefore the commencement of schooling for children, youth and adults, including girls and women must be given equal playing field (UIS, 2018). This situation will abide to order of achieving gender equality in education, the culture, policies, and practices of education need to reinvigorate (Galy-badenas \& Croucher, 2015). Among the main factors the research identified in Tanzania, that needs attention is the current societal and cultural attitudes of given prominent to educational boys school materials than girls' school, these stereotyped depictions of disparity early poor attitudes, which reinforce negative beliefs about women and perpetuate inequality. Traditions and old mentalities are affecting women education performance in Tanzania. Potentially, the syllabi of most sectors of education also need changes in teaching and learning materials at the primary school and literacy, to remove stereotypes and gender bias (Guidelines for Mainstreaming Gender in Literacy Materials, 2010).

\subsection{Background of the Study}

The phenomenon of gender inequality in education still exists in most of the world, especially Tanzania, the disparity gap that still exists between boys and girls are again widening in other developing countries. Girls are more vulnerable to boys; whiles education is the shared key to curtail human problems; efforts left in drawing board over the past decades needs strategic reforms. The international community and countries working abysmally to fulfill the promise to close the gender gap by 2030 remain a mirage. The situation has been tedious, scholarly UNESCO Institute for Statistics(UIS) disaggregates capacity indicators by sex to the effect possible, given parity indices and creative new indicators to better influence the equity and inclusion of girls and boys. A recent study from the UIS regularly data collected on the percentage of gender inequality within sub-Saharan Africa indicated that the professional teaching fraternity is lacking female teachers in both primary and secondary education worldwide (UIS, 2018). The Institutional collaborative research also found that educational inequality in higher levels realizes female to male still dispersed, more especially in the area of science, technology, engineering, and mathematics(STEM). These are not helpful to the phenomenon; such antecedence is not aimful to achieving the mapping data to close the educational pathways of gender from primary to tertiary education. There are sentiments of societal and cultural activities that abuse the extent to which girl's primary school; the factor of repetition grades, dropout rates makes the educational transition so difficult. The utilization of the multifunctional research from UIS to develop new measures; the study will better evaluate the readiness of governments across the African continent, especial Tanzania, building a viable foundation to abridge the gender inequality in education. The study policy aims to strategize some policies for government to curtail gender disparity and empower communities, cultures, countries, and stakeholders - all diverse field - to target initiatives and strategies better while benchmarking progress toward gender parity and equality (UIS, 2018).

The primary objective of the study is strategical disabuse the accelerated factors that affect gender inequality of education in Tanzania through government mien imperatives frames for socio-economic development. The teething research question is; what are the factors that accelerate gender inequality in the education system of Tanzania? What are the strategic government policies to resolve the phenomenon?

\section{Theoretical Framework on Gender Inequality}

The study choice of Social Role Theory (SRT) is influenced by the role perspective gotten from the overwhelmingly social psychology background envisage on feminine in societies attitudes, conformity, discrimination, belief, roles, expectations (Eagly \& Wood, 2012). The points that posit social functions and intertwined various social behaviors are; (1) role-related to individuals in groups, (2) with these groups taken entrench position, (3) each of this position distinctively outline are social roles. Again, (4) some formalized expectations become norms when individuals feel comfortable in providing reward and punishments. (5) Most people are generally conformist, which often conform to roles in society. (6) The expectations of reward and punishment inspire this conformity (Eagly \& Wood, 2012). The under listed important variables are related to measures for gender inequalities in our societies in our everyday life. By the UNESCO (2012), gender refers to the social roles, responsibilities, and behavior created in our communities and cultures. The concept considers the expectation held about the characteristics, attitudes, and behavior of male and female. For instance, 'men' as income earners and 'women 'as caregivers. The differential roles passed on from one generation to another. However, it is not biologically determined or fixed forever. They can change to achieve equity and equality for both men and women since gender is created by societies or communities and will change over time. This is 
because it carries the ideological of socio-cultural context in which it is constructed.

In brief, the research objective argues with the sex differences and similarities in behavior reflecting gender role base on societal beliefs misconception of men and women's roles in the communities in which they live (Eagly \& Wood, 2012). In post-industrial societies, often give priority to men than women in the field of employed, market, legislation, government especially in authority positions, and women left to fill caretaking roles at home (Grey, 2002). Naturally, men and women equally distributed into social functions, however, the belief and attitudes of humans' rotated physical sex differences uplifting men larger, faster, and have greater upper-body strength, and women gestate and nurse children (Raikes, Shoo, \& Brabin, 2016). Given the dimension of the social role theory, physical differences segregated, depending on belief systems and behaviors circumstances and culture, accomplishes certain activities. In all sectorial and communities the simple factor of gender inequality and transitional belief systems of women positions either open or closed belong to history. The aspect gives men an advantage in participating in public areas. This concept of gender is vital because it reveals how women's subordination and men's domination is socially and communally constructed (Simmonds \& Moore, 2006). Gender mainstreaming is critical to overcoming this. It will enable men and women to have access to opportunities at the same level playing ground with men. There are essential technical innovative on gender strategies are on competency for development vize; the awareness creation, intelligence, commitment and capacity necessary to incorporate gender perspectives into substantive work among professional staff (UNESCO, 2012).

Hypothesis

H1 the factors of gender inequality can influence women empowerment in the society.

$\mathbf{H 2}$ gender effects influence on women empowerment in policymaking and society.

H3 management strategies of gender inequality have a relationship with gender empowerment in the education system of Tanzania

\section{Methodology}

The study approach dual on qualitative for induction to accomplish the established research objective and question. The study design and techniques are conveniences due to the selected tertiary institutions in Tanzania and some communities. The target populations are students, communities' members and educational administrators. According to (Baxter \& Jack, 2008), research methodology is a systematic way of sorting and outline the research problem procedures to resolution. It is significant to note that the philosophy assumptions for any valid or reliable empirical science of studying the scientific and empirical to ascertain set out objectives. The researchers seek to qualitatively descriptive and interpret the empirical data using SPSS v.23 for the outcome (IBM, 2015), which is analyzed through the qualitative methodology of the data. Questionnaires in the survey adapted to measure participants' behavior using the 5score Likert scale (Beglar \& Nemoto, 2014). A sample size of 350 determination of the data revelation either satisfaction or otherwise in the course of the research. However, male 303 is $86.6 \%$, and female served 47 of $13.7 \%$, descriptive analyze the student satisfaction survey on demographics averages critical to the study of gender inequality to the education of Tanzania, from the communities especially universities selected in Tanzania. The response observation from the online survey gave more boys in tertiary level thank girls, and communities data checking were done in explaining the ideas in Swahili Language (Ingleby, 2012).

\subsection{Data Results and Analysis}

A qualitative design adopted in this study was to gain an in-depth understanding of the topic in the concession of gender inequality education of Tanzania and how government strategic management policies could avert the situation. The induction coded efficiently due to the Likert scale idea, classification, cleaning and entering data into the SPSS v.23. To determine the factors accelerating gender inequality in education and the management strategies gender inequalities towards women empowerment in the selected four higher learning institutions of SAUT, UDOM, MZUMBE, and TUMAIN University. Three hundred fifty participants via online and face-toface with community members out of which 200 were students from four institutions and 50 were vital educationist and 100 local community members as informants. The informants identified factors that accelerate gender inequality.

Table 2 Control variables of sex indicated justification of $86.6 \%$ of male to female of $13.4 \%$ in the higher institutions in which the data collected. The educated within the ages of (26-35years) gave the most elevated of $47.7 \%$ of the bachelor's levels of $55.4 \%$, the average age (16-25years) $25.7 \%$, (36-45years) and $25.4 \%$ orderly. The output represented the education indexes of $39.1 \%$ and $4.3 \%$ for masters' degrees and Ph.D. respectively. Table 2 shows most experiences educationist had more information about the existence of gender inequality and women empowerment in Tanzania. Age of an individual is among the key determinants of maturity and knowledge about being a leader. Accordingly, the researcher requested the respondents to state their ages in as much as age is significant to examine the relationships between their genders. The main concern of the study is 
gender inequality for the study. The responses of respondents in the study area were as indicated in Table 2 and Figure 2. The age significant to the study, due to the factor of education levels from primary, secondary to tertiary, the focus of the survey, enable government mien on the higher education for girls in Tanzania.

From the research findings, it established that the respondents' lowest age is 1 with $0.3 \%$ while the highest is 169 that is $47.7 \%$ in fig. 2 . The demographic age distribution of respondents indicated that $13 \%$ female within the range of 21-30 years. This demonstrated findings $87 \%$ male, within the age group of 26-30 years with the overall target been students. Further ranges the age group of 31-40 years male respondents constituted $25.4 \%$ while the female was $25.7 \%$ this group constituted administrative staff and students, $99.7 \%$ of the male are within the age group of (26-35) and (41-50) years while only $25.5 \%$ are female. Unfortunately percent of the male range within the age of $65 \%$ and above while the lowest percentage of female justifies the study significance. The facts suggest that the age of individuals fuels their involvements in a different position within the country as males occupy most of the administrative positions from the survey. The control variables findings are consistent with UNESCO number of age, adolescents, and youth who are expelled from education in the 2000 report indexes (UIS, 2018) (UNESCO Institute for Statistics, 2017). However, recent statistics from UIS data show that there has been progressing essentially for some developed economies. The research further outlined that, of out-of-school children, adolescents and female remained nearly the same thus 264 million for three years now (Figure 3 and Table 2). In another data analysis of which whooping number of 61 million, of which $23 \%$ are female of at the basic level-age (about 6 to 11 years). And, 62 million, of which $23 \%$ of the total, are adolescents of the high school-age (about 12 to 14 years), and 141 million, of which 53\% of our youth from the college and secondary education-age (about 15 to 17 years) (Benavot et al., 2016).

The result from the tables 3 above shows that most of the respondents ascertained that culture and tradition affect gender inequality in the education system of Tanzania as this factor is within the agreement level of $1.5-$ 3.4 average level. Cross-Examination of the aspects of the cultural practice of (Early marriage) limit access to educating girls showed an insignificant influence that can be associated with important issues of gender inequality in higher learning institutions. The cultural behavior barriers can be rectified through the strategic factor of policy and incentives to break the ginks of societies. The results supported by Mbekenga, (2013) who argued that a low number of female enrolled at class one affect higher education in the long run. Table 3 factors affecting gender inequality (FAW) is insignificant to gender/women empowerment, due to cultural and traditional perceptions.

Nevertheless, the effects of gender are significantly predictive of the factors affecting gender as well as strategies management of gender inequalities. This result from research view attributed to gender roles, and their results change from area to area depending on the determinant tradition and norms, cultural practices and values dominating the socializing agents (community) who assign the roles to a given group of people in the respective area as social role theory identified (Eagly \& Wood, 2012). From the same table 3 the effects on gender insignificant to women empowerment; however, predictively significant to strategy and factors of acceleration. Therefore, poverty as an effect showed the most cogent response as most of the respondents ascertained that poverty affects gender inequality in the education sector of Tanzania. In the same results from table 3 , the factors affecting gender (FAW) insignificant to women empowerment, but the strategic mainstreaming is significant to women empowerment in the societies and communities. Therefore, innovative strategies are a vital factor to accelerate gender disparities in Tanzania education. The correlation table 3 shows, MSG (management strategy on gender) is significant to variables in the achievement of gender inequalities. The research outcome in table 3 , shows GWE (gender/women empowerment), insignificant to factors (FAW), and effects (FFW) but significant with strategies (MSG) indication that the strategic streaming lining is recommended by this study for the achievement of least gender numbers in Tanzania education. Therefore, the study objective of strategic government policies of defeating gender inequality of Tanzania education is sustainable.

\subsection{Government Strategies Policies of Gender Inequality Education of Tanzania}

The study remained focus to optimize the analysis for the elimination of poverty and the provision of equal access to education in Tanzania for the sole purpose of empowering women. The study rudiments are therefore in line with the United Nations Sustainable Development Goals (SDGs) agenda for all developing nations (UIS, 2018). In the same development, a forum by UNESCO and Institute for Statistics UIS are hammering on the need for harnessing gender inequality for poverty eradication. The Global Education Monitoring (GEM) report also shows that education is pivotal for sustaining SDGs at such government policies for the sustainable achievements of equal education a forward move to empowering the agenda of women education and in the governmental sectors. The study policy strategies are; government establishment of free secondary education mainly for girls, emphatic on girl-child education. The elements to stimulating gender inequality in the educational barriers if societies are made to experience the significant position of women in decision-making in government. Such a phenomenon will affect communities and cultures. The concepts of scholarship incentive packages for the feminine in tertiary level to spur on the girl-child to attain higher education. As most of them 
fall-out-school due to poverty. In the same vein, culture is dynamic; sensitizations on some rituals that undermines the girl-child education for early marriages can be curtailed. Specifically, the power of influences from the families rest on the shoulder of women; their higher education positively affects the family and community. The other vital factors of gender inequality mitigated innovative grounds for illiterate's women through small-scale business to help keep the girl-child in school; subsequently, cash incentives for women groups will financial enhance the educational levels of women to promote the education system of Tanzania.

Table 4, investigated survey effect of gender inequality for women empowerment significantly influenced the regression model outcome the types of implications identified by respondents relied on social, political and economic sphere. Respondents asked as to whether gender inequality has any effect fig.4. All respondents in the study area ascertained the presence implications of gender inequality base these factors fig. 4 findings. The triangulated information from the data collection tools indicated that disparities had a profound impact, both positive and negative, on many accelerators including; motivation, productivity, participation, violence, and poverty as shown in fig. 4 . Therefore, the amalgamation of government strong strategic policies will mitigate the anomalies in the Tanzanian education system. The fig. 3 of path coefficient indicative of significant predictions among which management strategic shows strong $\beta=0.570^{* *}$ and gender effects $\beta=0.192 * *$ except factors for gender inequality $\beta=-0.006$. Eventually, the research objective of accentuating the strategic government policies for the elimination of gender disparity is acceptable using the social role theory. The management strategies conceptually will enhance the effective achievement of women empowerment for socio-economic, technological development of Tanzanian education.

\section{Discussions}

In this objective achievable through the social role theory, the research findings resulted in the management strategies applied by the government and the community towards gender equality and women empowerment. The concept of management strategies identified from the Primary level of education to higher education that could influence women empowerment and take advantage in various positions in Tanzania. The designated management strategies were however linked to what the society is practicing together to bring a gender balance. The different observation from interview among community members discussion revealed that there is a greater need for mainstreaming gender to ensure equal access to education in all levels of education in Tanzania. It is noted from the discussion that girls perform poorly all due to disparities comparison to boys with so much overburden household chores which makes them impossible to do adequate getting set with every time home duties to males. Mlama (2001) and Musisi, (2001) emphasized the strategic application in several African nations in higher education such as Ghana, Kenya, Malawi, Tanzania, and Zimbabwe. This strategy also needs to adapt to ordinary secondary education for the same purpose of increasing girl's enrolment in secondary school. The participant revealed that despite existing good plans, policies are an omen for the developing Republic of Tanzania that intend to ensure equal access of education still more gender-sensitive planning, and procedures needed to make the social mobilization to various groups of culture. The identified management strategies explained:

- Affordable Education to all Gender (Free education Program): The information from the community's discussion of poverty factor revealed that achieve gender equality in the education system of Tanzania, there is a need to make education affordable even at the secondary level. The study automation resolve that low-income families, which massively affect girl-child education absorb through free education policy.

- Provision of Incentive Program and Scholarships: General findings from discussion revealed that the current strategic policies are the most appropriate to bringing gender equality in education specifically in higher learning institutions to a close. The strategy identified by the respondents was the provision of Loans to disadvantaged groups to facilitate their studies in all fields of education, and the support for women groups in small-medium business to sustain.

This management strategy is a vital factor for governmental policy emphasize the National Agenda on Education, and Training Skills Policy of 2002, National Education Act of 1978 and the National Higher Education Policy of 1999 provide guidelines for achieving gender equity and equality in all levels of education (Hilsdon \& Randell, 2012). The High School Education Development Programme (2010 - 2015) suggested the issues of access and equity of women in higher education about the increased enrolment of female students especially in science and technology program, to enabling physical learning environments, loans, grants, and scholarships. The Tanzanian government is also a signatory to the UNESCO Convention against discrimination in education. The government has ratified the African Charter on Human and People's Rights (1981) and the Southern Africa Development Cooperation (SADC), Declaration on Gender and Human Rights (1997). Consistent with Chilisa study, (2002) observes that in Botswana and Ivory Coast where new policy allows childmothers to come back to school, it had $<20$ percentage \& $30 \%$ successful cases respectively. While evidence in Kenya also shows that less than 10\% return to school (Kimani \& Kombo, 2010). The researcher can conclude 
attitudes of educational workers affects students who get pregnant in school, which violates their fundamental human right and the restrictions in access to education.

Dollar \& Gatti (1999) who argued that Gender inequality decreases the average of Human Capital because unqualified males, which can lead to an inefficient economy, would supersede talented females also support the results. Klasen. (2002) On the other hand, argued that gender inequality in education lowest the mean of human resources in a society it turns to affect economic progression. It is abnormally restructuring the pool of talent from which to draw for education and thereby excluding highly qualified girls and taking less skilled boys instead (Dollar, Gatti, \& Filmer, 1999). Moreover, if there exist appearance of downward receptive in education, confining the girl-child education to the lowest minimal contrary taken boy-child education to the highest degree affecting the marginal return to gender disparity invariably lower boost of economic projections (World Bank 2001; Knowles et al. 2002) and (UNDP, 2014). Regarding gender gaps in employment, there is some relativity in different concepts. Besides, another disposition on the imposition of distorted economic averages to the gender gaps in the education of most developing states. Such phenomenon pulls down the skill talents from which employers can draw upon, thereby decreasing the average ability of the workforce Esteve-Volart 2004). Such educational gap or disparities affect the labor force, but similar arguments could be made for self-employed in agricultural and non-agricultural sectors where unequal access to critical inputs, technologies, and resources would reduce the average productivity of these ventures thereby reducing economic growth(Simavi, Manuel, \& Blackden, 2010).

In other studies conducted from the many secondary research from UIS, the study found youth in multiple folds than likely to be out of school as compared to children and twice likely to be out of school to adult girls. The high out-of-school rates for older cohorts also consistent with this research is related to poverty, policy, culture, ignorance and social norms: most of the dropout stage is the high school's education often not compulsory, and the most affected are the girl-child-youth. Which is affecting their human right to education in most developing countries (UIS, 2018)(UIS and GEM Report, 2016)? The statistics of the declining rates of outof-school on females, over the past 15 years is a redundancy reduction of gender disparity at the global stage (UNESCO Institute for Statistics, 2017). The studies from UIS showed that girls and young women are the most affected on the phenomenon of educational exclusion. The rate at which their male counterparts are affected less compared to the female in the inverse to girls education according to UIS and UNESCO. Therefore, the gender gap for secondary and primary school is accumulated widening for years to more than $5 \%$ since 2000 , less than $2 \%$ in 2015 .

\section{Conclusion}

Tanzania needs to develop learning curiosity among women and girls from the early stage of its development to catch up with emerging economies. Competition between girls and boys in schools disadvantages and leaves girls lagging in terms of educational achievements. Lowering entry cut off points for girls to be enrolled in higher education can reduce the gender gap and encourage them. Education is a right not a privilege of every citizen regardless of gender, color or geographical location. Several factors including poverty, cultural and tradition, power imbalance, wrong mentality, and education level pull girls away from the education system in Tanzania. Inequality in education led to poverty, violence, poor involvement in the development process, unequal distribution of resources due to vital corruption factor affecting systemic management of education. These affect not only the social welfare of the community but also the economic aspect of the whole nation, which translate into barriers of educational transformation. To ensure community and economic development in Tanzania gender inequality in education essential to addressed gender inequality education of Tanzania like making education affordable to all gender (free education) sensitization of the community, incentive program (scholarships) and promoting women in various positions. Therefore, the acceleration of gender inequality depends on the collective efforts of strategic government policies to empower women through education.

\section{References}

Baxter, P., \& Jack, S. (2008). The Qualitative Report Qualitative Case Study Methodology: Study Design and Implementation for Novice Researchers. The Qualitative Reportualitative Report, 13(2), 544-559. https://doi.org/citeulike-article-id:6670384

Beglar, D., \& Nemoto, T. (2014). Developing Likert-scale questionnaires. In JALT2013 Conference Proceedings (pp. 1-8).

Benavot, A., Antoninis, M., Bella, N., Delprato, M., Härmä, J., Jere, C., Zubairi, A. (2016). Education for All 2000 - 2015: The Influence of Global Interventions and Aid on EFA Achievements 1. The Handbook of Global Education Policy, 241-258.

Dollar, D., Gatti, R., \& Filmer, D. (1999). Gender inequality income and growth: Are good times good for women? Gender and Development, (1), 1-42. Retrieved from http://darp.lse.ac.uk/frankweb/courses/EC501/DG.pdf\%5Cnhttp://scholar.google.com/scholar?hl=en\&btn 
$\mathrm{G}=$ Search\&q=intitle:Gender+inequality,+income, + and+growth:+are+good+times + good+for+women?\#0

Eagly, A. H., \& Wood, W. (2012). Social role theory. Handbook of Theories of Social Psychology, (March), 458-476. https://doi.org/10.4135/9781446249222.n49

Entry, E. (2008). Mp r a. The World Bank Institute (WBI), Washington DC, USA, (7326).

Galy-badenas, F., \& Croucher, S. (2015). A Qualitative Study Of Male And Female Differences In The Working And Domestic Sphere : A comparison of the French and Finnish cultures ., 1-88.

Grey, S. (2002). Does Size Matter? Critical Mass and New Zealand's Women MPs. Parliamentary Affairs. https://doi.org/10.1093/parlij/55.1.19

Guidelines for Mainstreaming Gender in Literacy Materials. (2010).

Hilsdon, A.-M., \& Randell, S. (2012). Application of the Recommendations concerning Teaching Personnel (CEART), held in Geneva, (October), 8-12. Retrieved from https://www.ilo.org/wcmsp5/groups/public/--ed_dialogue/---sector/documents/meetingdocument/wcms_214122.pdf

HRC-Pakistan. (2015). State of Human Rights in 2015. Human Rights Commission of Pakistan (Vol. 21).

IBM. (2015). SPSS Software. Predictive Analytics Software and Solutions, 1. Retrieved from http://www01.ibm.com/software/analytics/spss/

Ingleby, E. (2012). Research methods in education. Professional Development in Education, 38(3), 507-509. https://doi.org/10.1080/19415257.2011.643130

Kimani, E. N., \& Kombo, D. K. (2010). Gender and poverty reduction: A Kenyan context. Educational Research and Reviews, 5(1), 24-30. $\quad$ Retrieved http://www.ku.ac.ke/schools/humanities/images/stories/docs/Research/gender-and-poverty-reduction.pdf

Lewin, K. M., \& Little, A. W. (2011). Access to education revisited: Equity, drop out and transitions to secondary school in South Asia and Sub-Saharan Africa. International Journal of Educational Development, 31(4), 333-337. https://doi.org/10.1016/j.ijedudev.2011.01.011

Raikes, A., Shoo, R., \& Brabin, L. (2016). Gender-planned health services. Annals of Tropical Medicine \& Parasitology, 86(sup1), 19-23. https://doi.org/10.1080/00034983.1992.11812731

Reid, J. A., \& Shams, T. (2013). Gender and multigenerational global human development. Sociology Compass, 7(8), 612-629. https://doi.org/10.1111/soc4.12060

RTI International. (2016). A Guide for Strengthening Gender Equality and Inclusiveness in Teaching and Learning Material. In A Guide For Strengthening Gender Equality And Inclusiveness In Teaching And Learning Materials (pp. 1-28). Washington, DC: U.S. Agency for International Development.

Simavi, S., Manuel, C., \& Blackden, M. (2010). Gender Dimensions of Investment Climate Reform A Guide For Policy Makers And Practitioners (Vol. 1). Retrieved from http://www.ifc.org/wps/wcm/connect/ec3a5f004885538eaf94ff6a6515bb18/Gender_IC_reform_book.pdf? MOD $=$ AJPERES

Simmonds, C. A., \& Moore, S. L. (2006). Androgyny, femininity, and masculinity in women: exploring how gender role and personality relate to paranormal experiences, beliefs, and ESP. 30th International Conference Ofthe Society for Psychical Research.

Simwaka, B., Theobald, S., Amekudzi, Y., \& Tolhurst, R. (2005). Meeting Millennium Development Goals 3 and 5: Gender Equality Needs To Be Put on the African Agenda. BMJ, 331, 708-709. https://doi.org/10.1136/bmj.331.7519.708

Sumra, S. (2017). The impact of the implementation of fee-free education policy on basic education in Tanzania. Ethnic Technology Notes, (8), 27.

TARGET, G. A. (2015). Sustainable Development Goals and targets. International Council for Science, 4.

The Lancet. (2018). Closing the gender pay gap: when and how? The Lancet, 391(10129), 1455. https://doi.org/10.1016/s0140-6736(18)30837-7

UIS. (2018). One in Five Children, Adolescents, and Youth in Out of School. Unesco Institute for Statistics, Fact Sheet(48), 13. https://doi.org/10.1177/0093854814546894

UN Development Taskforce. (2011). Gender Equality and Women's Empowerment.

UNDP. (2014). Development for Empowerment. The 2014 Palestine Human Development Report. Retrieved from PHDR2015Education.pdf

UNESCO Institute for Statistics. (2017). Literacy Rates Continue to Rise from One Generation to the Next. Unesco, 2016(45), 1-13. Retrieved from http://on.unesco.org/literacy-map.

United Nations Educational Scientific and Cultural Organization. (2018). Global Education Monitoring Report Gender Review 2018: Meeting our commitments to gender equality in education. Global Education Monitoring Report 2017/18. Retrieved from http://unesdoc.unesco.org/images/0026/002615/261593E.pdf 
Table 1. The conceptual variables measures in the study

\begin{tabular}{|c|c|}
\hline Variables in the Study & Measured factors \\
\hline Factors for gender inequality(Entry, 2008) & $\begin{array}{ll}\text { - } & \text { Power Imbalance } \\
\text { - } & \text { Bad mentality } \\
\text { - } & \text { Educational level } \\
\text { - } & \text { Traditional and culture } \\
\text { - } & \text { Poverty }\end{array}$ \\
\hline Effects of gender inequalities(Lewin \& Little, 2011) & $\begin{array}{l}\text { - } \quad \text { Poor involvement of women } \\
\text { - Unequal distribution of resources } \\
\text { - } \quad \text { Poor treatment for women } \\
\text { - Violence against women } \\
\text { - Poverty }\end{array}$ \\
\hline $\begin{array}{l}\text { Management strategies for gender inequality(The } \\
\text { Lancet, 2018) }\end{array}$ & 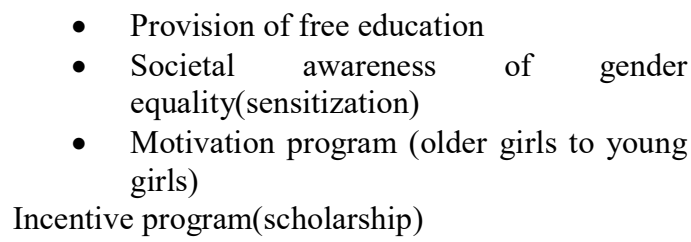 \\
\hline $\begin{array}{l}\text { Gender equality / Women } \\
\text { Development Taskforce, 2011) }\end{array}$ & $\begin{array}{l}\text { - Improving the quality of life } \\
\text { - } \text { Improving socio-economic and political } \\
\text { - } \quad \text { The ability to respond to challenges } \\
\text { - } \quad \text { Enhanced women career mobility } \\
\text { - Improved women access } \\
\text { - Women professional treatment }\end{array}$ \\
\hline
\end{tabular}

Variables measures and explanations

Table 2. Demographic data of the study

\begin{tabular}{|c|c|c|c|c|c|}
\hline \multicolumn{2}{|c|}{ Control Variables } & \multirow{2}{*}{$\begin{array}{r}\text { Frequency } \\
47\end{array}$} & \multirow{2}{*}{$\begin{array}{r}\text { Percent } \\
13.4\end{array}$} & \multirow{2}{*}{$\begin{array}{r}\text { Valid Percent } \\
13.4\end{array}$} & \multirow{2}{*}{$\begin{array}{r}\text { Cumulative Percent } \\
13.4\end{array}$} \\
\hline SEX_D & FEMALE & & & & \\
\hline & MALE & 303 & 86.6 & 86.6 & 100.0 \\
\hline & Total & 350 & 100.0 & 100.0 & \\
\hline \multirow[t]{5}{*}{ AGE } & $16-25 y r s$ & 90 & 25.7 & 25.8 & 25.8 \\
\hline & $26-35 y r s$ & 167 & 47.7 & 47.9 & 73.6 \\
\hline & $36-45 y r s$ & 89 & 25.4 & 25.5 & 99.1 \\
\hline & 46above & 3 & .9 & .9 & 100.0 \\
\hline & Total & 349 & 99.7 & 100.0 & \\
\hline Missing & System & 1 & .3 & & \\
\hline Total & & 350 & 100.0 & & \\
\hline \multirow[t]{6}{*}{ JOBS } & NGOS & 58 & 16.6 & 16.7 & 16.7 \\
\hline & SELF-EMPLOYED & 235 & 67.1 & 67.5 & 84.2 \\
\hline & PUBLIC & 28 & 8.0 & 8.0 & 92.2 \\
\hline & PRIVATE & 11 & 3.1 & 3.2 & 95.4 \\
\hline & OTHERS & 16 & 4.6 & 4.6 & 100.0 \\
\hline & Total & 348 & 99.4 & 100.0 & \\
\hline Missing & System & 2 & .6 & & \\
\hline Total & & 350 & 100.0 & & \\
\hline \multirow[t]{5}{*}{ EDUCATION } & HIGH SCHOOL & 3 & .9 & .9 & .9 \\
\hline & BACHELOR & 194 & 55.4 & 55.6 & 56.4 \\
\hline & MASTERS' & 137 & 39.1 & 39.3 & 95.7 \\
\hline & $\mathrm{PhD}$ & 15 & 4.3 & 4.3 & 100.0 \\
\hline & Total & 349 & 99.7 & 100.0 & \\
\hline Missing & System & 1 & .3 & & \\
\hline Total & & 350 & 100.0 & & \\
\hline
\end{tabular}




\begin{tabular}{llrrrr}
\hline Control Variables & Frequency & Percent & Valid Percent & Cumulative Percent \\
\hline EXPERIENCE & $1-5 y r s$ & 111 & 31.7 & 31.7 & 31.7 \\
& 6-10yrs & 62 & 17.7 & 17.7 & 49.4 \\
11-15yrs & 117 & 33.4 & 33.4 & 82.9 \\
16-20yrs & 56 & 16.0 & 16.0 & 98.9 \\
& 21above & 4 & 1.1 & 1.1 & 100.0 \\
& Total & 350 & 100.0 & 100.0 & \\
\hline
\end{tabular}

Descriptive control variables used in the study.

Table 3. Correlation of the Variables in the gender inequalities of Tanzania Correlations

\begin{tabular}{|ll|r|r|r|r|}
\hline & \multicolumn{1}{|c|}{ FAW } & \multicolumn{1}{c|}{ FFW } & \multicolumn{1}{c|}{ MSG } & \multicolumn{1}{c|}{ GWE } \\
\hline FAW & Pearson Correlation & 1 & $-.245^{* *}$ & $-.144^{* *}$ & -.041 \\
& Sig. (2-tailed) & & .000 & .008 & .448 \\
& N & 341 & 341 & 340 & 340 \\
\hline FFW & Pearson Correlation & $-.245^{* *}$ & 1 & $.374^{* *}$ & .031 \\
& Sig. (2-tailed) & .000 & & .000 & .568 \\
& N & 341 & 350 & 349 & 347 \\
\hline MSG & Pearson Correlation & $-.144^{* *}$ & $.374^{* *}$ & 1 & $.527^{* *}$ \\
& Sig. (2-tailed) & .008 & .000 & & .000 \\
& N & 340 & 349 & 349 & 347 \\
\hline GWE & Pearson Correlation & -.041 & .031 & $.527^{* *}$ & 1 \\
& Sig. (2-tailed) & .448 & .568 & .000 & \\
& N & 340 & 347 & 347 & 347 \\
\hline
\end{tabular}

**. Predictive significant at the 0.01 level (2-tailed).

Note: $F A W=$ Effects of gender inequality, $F F W=$ factors affecting gender inequalities, $M S G=$ management strategies for gender inequalities, GWE = Gender/Women Empowerments

Table 4. Regression Model Results

Model Summary

\begin{tabular}{|c|c|c|c|c|c|c|c|c|c|}
\hline \multirow[b]{2}{*}{ Model } & \multirow[b]{2}{*}{$\mathrm{R}$} & \multirow[b]{2}{*}{$\begin{array}{c}\text { R } \\
\text { Square }\end{array}$} & \multirow[b]{2}{*}{$\begin{array}{l}\text { Adjusted R } \\
\text { Square }\end{array}$} & \multirow{2}{*}{$\begin{array}{l}\text { Std. The } \\
\text { error of the } \\
\text { Estimate }\end{array}$} & \multicolumn{5}{|c|}{ Change Statistics } \\
\hline & & & & & $\begin{array}{l}\text { R Square } \\
\text { Change }\end{array}$ & $\begin{array}{c}\mathrm{F} \\
\text { Change }\end{array}$ & df1 & df2 & $\begin{array}{c}\text { Sig. F } \\
\text { Change }\end{array}$ \\
\hline 1 & $.538^{\mathrm{a}}$ & .290 & .283 & 5.78406 & .290 & 45.688 & 3 & 336 & .000 \\
\hline
\end{tabular}

a. Predictors: (Constant), MSG, FAW, FFW

b. Dependent Variable: GWE

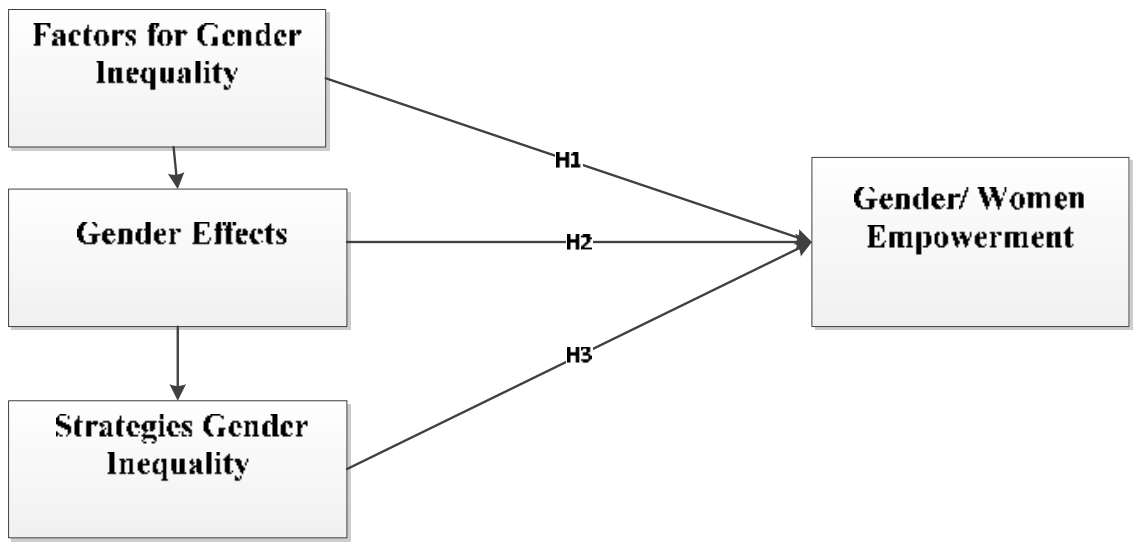

1. Conceptual Study Framework 


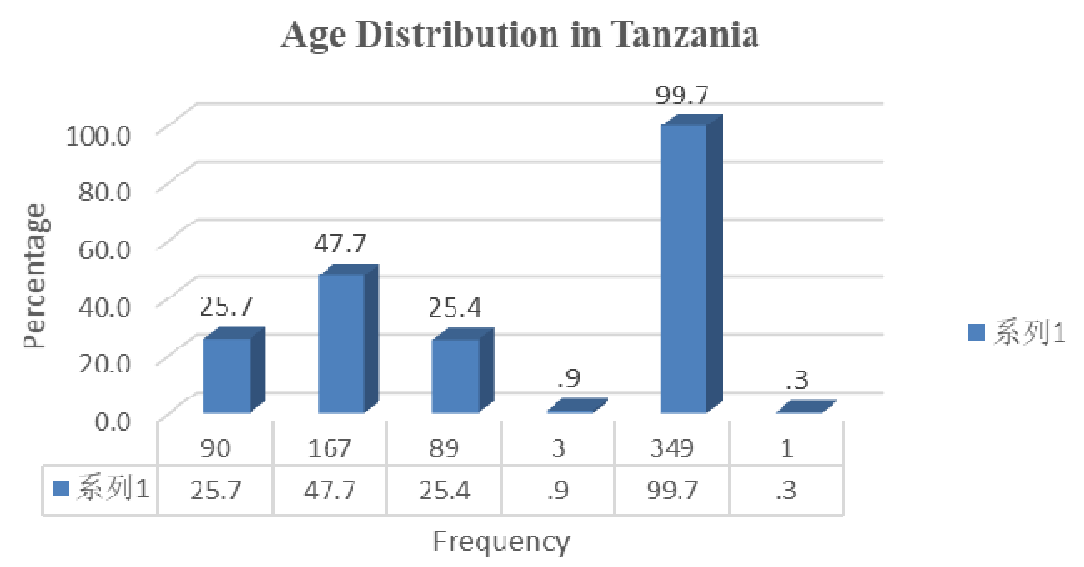

Fig. 2. Age Respondents in the Study

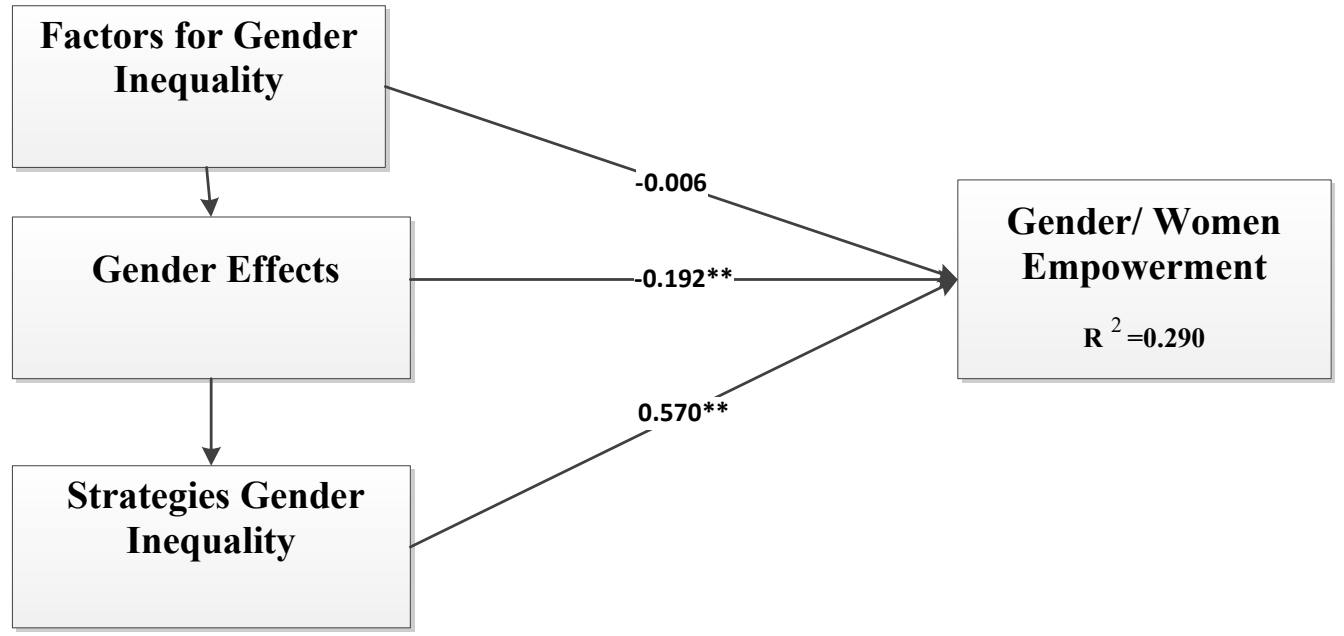

Fig 3. Path Coefficient of the Hypotheses of the Study

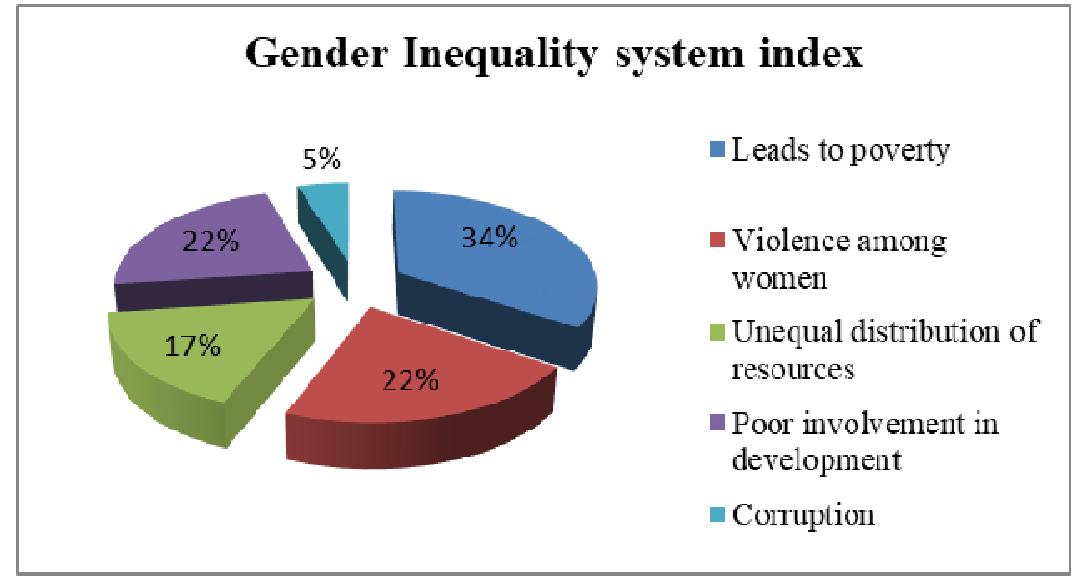

Fig 4. Impacts of Gender Inequality in the Education System 